\title{
PLANO DE MANEJO E DESENVOLVIMENTO: A EXPERIÊNCIA DOS \\ COMUNITÁRIOS DA RESEX DO CIRIACO NA IMPLEMENTAÇÃO DE PROJETOS
}

Management and development plan: the experience of Ciriaco Resex communities in implementing projects

DOI: 10.48075/igepec.v25i1.24980

Lucélia Neves

Alex Pizzio

Waldecy Rodrigues 


\title{
PLANO DE MANEJO E DESENVOLVIMENTO: A EXPERIÊNCIA DOS COMUNITÁRIOS DA RESEX DO CIRIACO NA IMPLEMENTAÇÃO DE PROJETOS
}

\author{
Management and development plan: the experience of Ciriaco Resex communities \\ in implementing projects
}

DOI: 10.48075/igepec.v25i1.24980

\author{
Lucélia Neves \\ Alex Pizzio \\ Waldecy Rodrigues
}

\begin{abstract}
Resumo: Este trabalho tem o objetivo de discorrer sobre os projetos desenvolvidos (por meio de recursos públicos e/ou privados) na Reserva Extrativista (Resex) do Ciriaco, localizada no município de Cidelândia (MA) e averiguar se a implementação destes está condizente com as recomendações determinadas em seu Plano de Manejo. Nesse sentido, foram levantados os planos executados no recorte temporal de 1996 a 2020, conforme a fonte do recurso, a finalidade e o valor destinado. Foi utilizada a abordagem qualitativa, com técnicas de pesquisa bibliográficas e exploratórias. Os resultados revelaram que os projetos têm propósitos distintos e buscam atender às dinâmicas socioeconômica e ambiental na região em que está inserida a Resex do Ciriaco. Concluiu-se que os comunitários, por meio do Conselho Deliberativo e da Associação dos Agroextrativistas, prezam pelas normas estabelecidas no Plano de Manejo e buscam junto às organizações (setor público ou setor empresarial) essa conformidade na execução de cada projeto.
\end{abstract}

Palavras-chave: Plano de manejo; Desenvolvimento; Participação.

\begin{abstract}
This work aims to discuss the projects (public and / or private) developed in the Extractive Reserve (Resex) of Ciriaco, located in the city of Cidelândia (MA) and to verify if their implementation is consistent with the recommendations determined in its Plan of Action. Management. In this sense, the plans executed in the time frame from 1996 to 2020 were raised, according to the source of the resource, the purpose and the amount allocated. The qualitative approach was used, with bibliographic and exploratory research techniques. The results revealed that the projects have different purposes and seek to meet socioeconomic and environmental dynamics in the region where Ciriaco's Resex is located. It was concluded that community members, through the Deliberative Council and the Association of Agroextractivists, value the rules established in the Management Plan and seek from organizations (public sector or business sector) this conformity in the execution of each project.
\end{abstract}

Keywords: Management plan; Development; Participation.

Resumen: Este trabajo tiene como objetivo discutir los proyectos (públicos y / o privados) desarrollados en la Reserva Extractiva (Resex) de Ciriaco, ubicada en la ciudad de Cidelândia (MA) y verificar si su implementación es consistente con las recomendaciones determinadas en su Plan de Acción. Administración. En este sentido, se plantearon los planes ejecutados en el plazo de 1996 a 2020, de acuerdo con la fuente del recurso, el propósito y la cantidad asignada. Se utilizó el enfoque cualitativo, con técnicas de investigación bibliográfica y exploratoria. Los resultados revelaron que los proyectos tienen diferentes propósitos y buscan cumplir con las dinámicas socioeconómicas y ambientales en la región donde se encuentra Resex de Ciriaco. Se concluyó que los miembros de la comunidad, a través del Consejo Deliberativo y la Asociación de Agroextractivistas, valoran las reglas establecidas en el Plan de Gestión y buscan de las organizaciones (sector público o sector empresarial) esta conformidad en la ejecución de cada proyecto.

Palabras clave: Plan de gestión; Desarrollo; Participación. 
Informe GEPEC, ISSN: 1679-415X, Toledo, v. 25, n.1, p.10-26, jan./jun. 2021.28 


\section{INTRODUÇÃO}

As Reservas Extrativistas (Resex) foram criadas para garantir o uso sustentável da biodiversidade, bem como para proteger a cultura das comunidades. Assim, desenvolver estratégias de governança comunitária para o uso equilibrado dos bens comuns de uma Resex é condição essencial para os atores envolvidos alcançarem atitude e consciência ambiental, contribuindo para a sustentabilidade da biodiversidade e, por conseguinte, com o impacto positivo na qualidade de vida dos comunitários, a partir da dinâmica de seus projetos. Para tanto, na implementação de projetos e/ou programas na área de uma reserva extrativista, é indispensável a adequação às regras estabelecidas em seu plano de manejo.

Em seu site, o Ministério do Meio Ambiente (MMA) define o plano de manejo, como "um documento consistente, elaborado a partir de diversos estudos, incluindo diagnósticos do meio físico, biológico e social. Ele estabelece as normas, restrições para o uso, ações a serem desenvolvidas e manejo dos recursos naturais das unidades de conservação e seu entorno" (BRASIL, 2020).

Nesse sentido, a implementação de projetos pode ser considerada também como oportunidade para atender a uma demanda social e/ou ambiental e até mesmo uma demanda legal. Por esse motivo, as atividades devem ser iniciadas, desenvolvidas e concluídas visando o bem-estar das comunidades.

Este estudo tem como objetivo discorrer sobre os projetos desenvolvidos (por meio de recursos públicos e/ou privados) na Reserva Extrativista do Ciriaco, unidade de conservação (UC) federal classificada na categoria das unidades de uso sustentável, localizada no município de Cidelândia/MA, para averiguar se a implementação destes segue as recomendações determinadas em seu plano de manejo. Para tanto, foram levantados os projetos implementados entre 1996 e 2020, conforme a fonte do recurso, a finalidade e o valor destinado. Cabe ressaltar que a Resex em questão tem o seu plano de manejo, ${ }^{1}$ o qual se constitui no documento de base para orientar a implementação e a gestão dos projetos a serem desenvolvidos. Esse plano de manejo pressupõe as "ações necessárias para a gestão e uso sustentável dos recursos naturais em qualquer atividade no interior e em áreas do entorno dela de modo a conciliar, de maneira adequada e em espaços apropriados, os diferentes tipos de usos com a conservação da biodiversidade" (ICMBIO, 2020).

Os projetos ali existentes foram implementados a partir do empenho dos comunitários membros da Associação dos Trabalhadores Agroextrativistas da Resex do Ciriaco (Atareco), do Instituto Chico Mendes de Conservação da Biodiversidade (ICMBio). Posteriormente, depois de criado, o plano contou com a participação dos integrantes do Conselho Deliberativo (representado pela sociedade civil, poder público e instituições de pesquisa) além de outros atores sociais. A fonte dos recursos destinados aos projetos tem procedência tanto do setor público como do setor privado e, ainda, do terceiro setor (ISPN, Fundo Amazônia, PNUD, Eletronorte, Incra e Suzano Papel e Celulose), ou seja, com origem nacional e internacional.

Esclarece-se que, neste artigo, os termos comunidade e comunitários serão utilizados para definir a área da reserva extrativista pesquisada, bem como as pessoas que nela residem, respeitando a diversidade sociocultural do Brasil e as várias categorias dos grupos humanos.

\footnotetext{
${ }^{1}$ A elaboração do referido plano teve início em março de 2009 e se estendeu até outubro de 2010.
} 


\section{REVISÃO DE LITERATURA}

Esta seção apresenta os conceitos teóricos que fundamentam as regras estabelecidas no Plano de Manejo Participativo da Resex do Ciriaco, relacionando-os à teoria da governança dos comuns (OSTROM, 2011).

\subsection{A sustentabilidade dos recursos naturais de uso comum (RUC)}

O Ministério do Meio Ambiente caracteriza reserva extrativista como uma categoria de unidade de conservação federal de uso sustentável, estabelecida pela Lei $n^{0}$ 9.985/2000 (Lei do Sistema Nacional de Unidades de Conservação - SNUC).

Assim, a Reserva Extrativista de Ciriaco no Estado do Maranhão foi criada pelo Decreto $\mathrm{n}^{0}$ 534, de 20 de maio de 1992, está localizada no município de Cidelândia e pertence ao bioma Amazônia. Com área inicial de 7.050 hectares, a reserva teve sua ampliação concedida em 2010 e, atualmente, possui uma área de 8.106,75 hectares. O projeto contemplou aproximadamente 350 famílias distribuídas nas comunidades de Ciriaco, Centro do Olímpio, Alto Bonito e Viração.

Para o Ministério do Meio Ambiente o Plano de Manejo Participativo é um documento coeso que estabelece as normas e as restrições para nortear os comunitários (residentes) sobre o uso sustentável dos recursos naturais da Resex do Ciriaco (BRASIL, 2011). Tais normas e regras foram discutidas entre os comunitários e elaboradas por representantes da Associação dos Trabalhadores Agroextrativistas da Reserva Extrativista de Ciriaco - Atareco, do Centro de Educação e Cultura do Trabalhador Rural - CENTRU/MA, e do Movimento Interestadual de Mulheres Quebradeiras de Coco Babaçu - MIQCB coordenação Imperatriz. Com o apoio financeiro do Programa ARPA - MMA, da Agência de Cooperação Técnica Alemã GTZ (atual GIZ) e do Fundo Mundial para Natureza - WWF (ICMBIO, 2011).

O Plano de Manejo Participativo da Resex do Ciriaco (ICMBIO, 2011, p. 17) é um documento que "visa dar apoio concreto à gestão da Unidade de Conservação [...], o mesmo deve estar coadunado [...] em termos sociais e econômicos, identificando temas mais urgentes e orientando a gestão com visão de futuro no longo prazo”. O referido Plano (2011, p. 18) tem o propósito de nortear os comunitários quanto às informações estruturais à gestão da Resex e devem ser apropriadas para:

$\checkmark$ Direcionar a Unidade de Conservação para alcançar sua visão de futuro no longo prazo;

$\checkmark$ Vincular-se às situações específicas da UC, buscando êxito para as ações mais urgentes;

$\checkmark$ Refletir a situação a ser alcançada durante a vigência do plano;

$\checkmark$ Manter estreita relação com os objetivos da categoria de manejo e sua missão;

$\checkmark$ Ser revisados a cada novo ciclo de gestão da UC;

$\checkmark$ Considerar as limitações, fortalezas e a capacidade de gestão da UC;

$\checkmark$ Considerar a dinâmica socioambiental da UC; e,

$\checkmark$ Conduzir a resultados concretos de gestão.

Nessa lógica, as atividades devem ser iniciadas, desenvolvidas e concluídas considerando-se as limitações, a capacidade de gestão e, fundamentalmente, atender à dinâmica socioambiental da Resex. Conforme determinação do Ministério do Meio 
Ambiente, a utilização das reservas extrativistas é concedida às comunidades extrativistas tradicionais que tenham sua subsistência garantida por meio do extrativismo ou na atividade mista do agroextrativismo. Os principais objetivos visam garantir o uso sustentável dos recursos naturais da unidade, proteger os meios de vida e a cultura destas comunidades (BRASIL, 2011).

\subsection{A governança ambiental na Resex do Ciriaco}

A teoria da governança dos comuns (em inglês, common pool resource - CRP), apresentada pela economista e Prêmio Nobel de Ciências Econômicas em 2009, Elinor Ostrom, comprova que os grupos utilizadores de bens comuns (recursos naturais) são capazes de estabelecer regras e mecanismos eficientes que disciplinam a exploração destes. Seu trabalho chama atenção para a concepção de que algumas comunidades locais desenvolvem, de forma eficiente, a gestão dos bens comuns sem a necessidade de seguir as regras impostas por programas governamentais ou em parceria com a iniciativa privada.

E, para solucionar os conflitos presentes na gestão dos recursos comuns, a comunidade deve se organizar e buscar a cooperação mútua entre os envolvidos, sejam estes indivíduos ou instâncias que utilizam os mesmos bens, visando a sua sustentabilidade (HESS; OSTROM, 2007).

Nessa perspectiva, a teoria da governança dos comuns, de Ostrom, cita dezenas de casos de governança comunitária que deram certo em países como Suíça, Japão, Turquia e Canadá, onde foi verificado o uso comum de: bacias hidrográficas, florestas, áreas de pesca, superfície de terra, entre outros. No percurso das pesquisas, a autora constatou casos de sucesso e também de insucesso, aplicou estudo comparativo e estabeleceu os oito princípios da teoria da governança:

i) Demarcação clara das fronteiras dos recursos de bem comum e de seus utilizadores;

ii) Definição das regras adequadas às condições locais (época, espaços, tecnologias disponíveis, quantidades de recursos disponíveis...);

iii) Participação dos utilizadores na definição/adaptação das próprias regras, acordos coletivos;

iv) Proporcionalidade entre os fluxos de benefícios proporcionados pela gestão comum e os custos de utilização;

v) Reconhecimento das regras da comunidade pelas autoridades externas;

vi) Realização de monitoramento e são respeito às regras por parte dos utilizadores, com penalizações para os transgressores;

vii) Garantia de fácil acesso aos meios de resolução de conflitos bem como a custos reduzidos;

viii) Ligação na gestão de recursos de menor escala com os de maior escala, partindo do particular para o geral (OSTROM, 1990, p. 90-102, tradução nossa).

A Reserva Extrativista do Ciriaco apresenta, em sua realidade, um cenário promissor ao desenvolvimento de projetos de acordo com os princípios mencionados. Cerca de 90\% dos proprietários da área foram indenizados, o que possibilitou que cada uma dessas 350 famílias de extrativistas utilizasse um espaço para executar suas 
atividades e, dessa forma, pudesse participar na definição e adaptação das próprias regras, mediante acordos coletivos.

A demarcação das fronteiras dos recursos de bem comum viabilizou as estratégias de governança comunitária e a participação efetiva do Conselho Deliberativo da Reserva Extrativista de Ciriaco. Isso potencializou, portanto, o alcance de sua finalidade: contribuir com ações voltadas à efetiva implantação e implementação do plano de manejo dessa UC federal, bem como o cumprimento de seus objetivos de criação.

Ainda assim, os obstáculos existem, conforme o levantamento realizado a partir das informações disponibilizadas pelo gestor da Resex do Ciriaco (ICMBio) nos últimos anos. As transgressões às normas do Plano de Manejo são resultantes da postura de parte de comunitários que não cumprem determinadas regras estabelecidas no referido documento. Contudo, os conflitos endógenos, como a prática de queimadas, a criação de gado além do número permitido e eventuais desmatamentos da mata ciliar dos córregos da Resex, na maioria das vezes, são contornados por meio de discussões conjuntas nas reuniões do Conselho Deliberativo e da orientação de técnicos das áreas ambiental, agricultura e pecuária, buscando-se o encaminhamento adequado para estas questões:

Os problemas de conservação dos recursos naturais vêm evoluindo, pois, na Resex alguns moradores, ainda insistem na criação de gado. A proposta de Plano de uso da unidade permite a criação para fins de segurança alimentar de até 10 (dez) animais por família, mas alguns deles muitas vezes extrapolam o limite, extrapolam as quantidades permitidas para pasto, acarretando sansões administrativas (multa, embargo, etc.) (FERREIRA, 2016, n.p).

Contudo, a comunidade se mobiliza diante desses obstáculos e muitos dos moradores auxiliam na proteção e na conservação da UC federal denunciando práticas ilícitas que não condizem com os acordos estabelecidos entre os atores.

Como fator exógeno que causa impacto negativo na conservação dos recursos naturais, o gestor da Resex ressaltou a influência de práticas adotadas pelos proprietários de fazendas e por membros das comunidades localizadas no entorno da comunidade do Ciriaco, pois, no entorno, as atividades de pecuária e silvicultura são amplamente desenvolvidas sem monitoramento dos órgãos competentes (agricultura, pecuária, meio ambiente):

Se dá no entorno, com as práticas de pecuária e silvicultura (eucalipto), o aumento das atividades econômicas na região. Nos últimos anos tem se acentuado o tráfego de veículos e pessoas na unidade, trazendo consequências negativas como o aumento da caça ilegal, do desgaste do solo, das quantidades de lixo produzido e do uso inadequado das águas (FERREIRA, 2016, n.p.).

Diante desse contexto, os obstáculos existentes na Resex representam uma oportunidade para a atuação dos moradores visando atender à demanda social e ambiental, bastante relevantes para as comunidades de Ciriaco, Cento do Olympio, Bom Jesus, Alto Bonito e Viração. Mesmo em caráter temporário, os projetos 
implantados são desejáveis pelas comunidades e necessitam de novos investimentos em suas iniciativas.

\section{METODOLOGIA}

Para a realização desta pesquisa foi empregada a abordagem qualitativa, considerando que esse tipo de análise, segundo Godoy (1995, p. 58), "não procura enumerar e/ou medir os eventos estudados, nem emprega instrumental estatístico na análise dos dados, envolve a obtenção de dados descritivos sobre pessoas, lugares e processos interativos".

A referida pesquisa, quanto aos fins, pode ser considerada como exploratória, pois foi realizada em área de pouco conhecimento sistematizado; dessa forma, não coube elaborar hipóteses em sua fase inicial.

Quanto aos meios, a pesquisa classifica-se como bibliográfica, pois foi realizada uma revisão de literatura sobre o tema gestão de projetos e governança dos bens comuns (VERGARA, 2016).

Nessa perspectiva, a pesquisa bibliográfica foi pautada nas obras de Elinor Ostrom $(1990,1999)$, contemplando as áreas de economia ecológica, e nas informações contidas no Plano de Manejo Participativo da Reserva Extrativista do Ciriaco (ICMBIO, 2011), para assimilar informações essenciais à elaboração deste estudo.

A pesquisa também foi complementada por dados coletados com o representante do ICMBio - Unidade de Imperatriz/MA, que detalhou a experiência dos comunitários da Resex de Ciriaco (MA) e demais atores (ICMBio, Conselho Deliberativo e ATARECO) envolvidos na gestão de projetos executados no período de 1996 a 2020, nas comunidades: Ciriaco, Centro do Olímpio, Alto Bonito e Viração. Portanto, a metodologia desta pesquisa reuniu técnicas de pesquisa bibliográfica e levantamento de dados primários e secundários.

Figura 1 - Caracterização da área de estudo

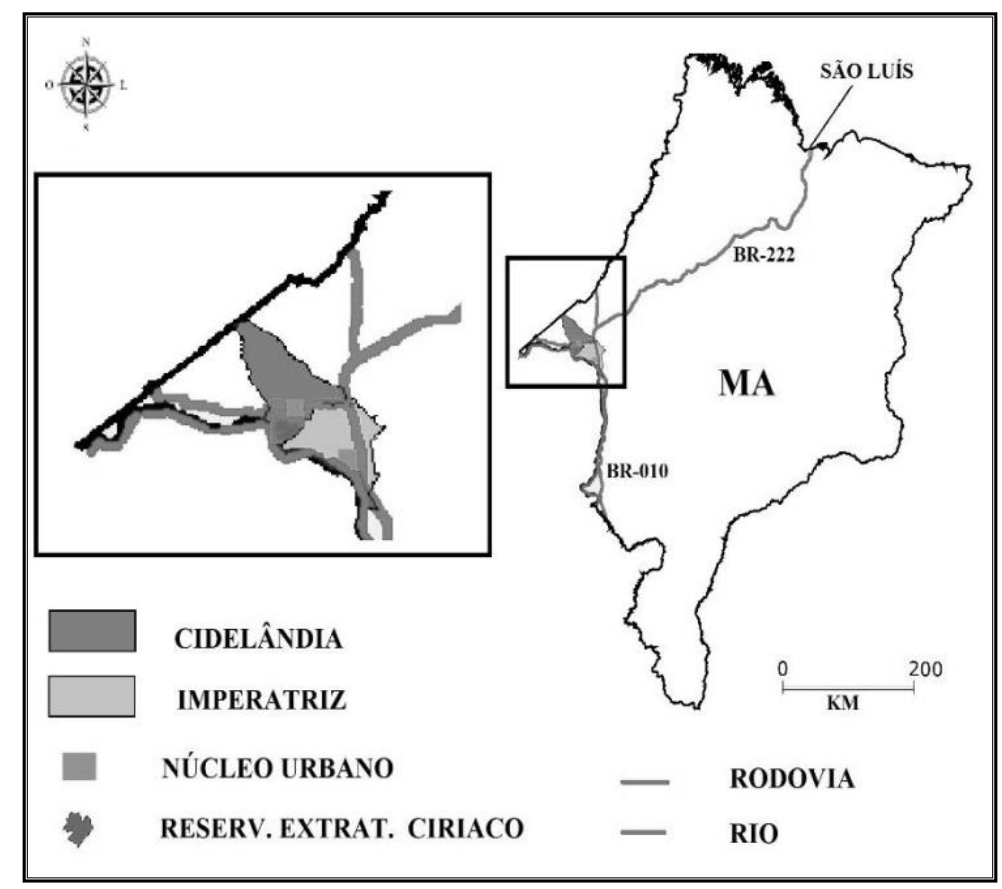

Fonte: Oliveira (2017). 
A Reserva Extrativista do Ciriaco, conforme apresentada na Figura 1, está localizada na zona rural do município de Cidelândia (MA), onde aproximadamente 350 famílias de agroextrativistas residem nas comunidades Ciriaco, Centro do Olímpio, Alto Bonito e Viração. Salienta-se que o Agroextrativismo é uma atividade de produção que combina o extrativismo do coco de babaçu com a agricultura familiar, sendo bastante praticada na Resex do Ciriaco, conforme constatado na pesquisa/20172020.

Ciriaco foi criada por meio do Decreto $\mathrm{n}^{0} 534$, de 20 de maio de 1992, e pertence ao bioma Amazônia. Possui uma área de 8.106,75 hectares, estando situada a $78 \mathrm{~km}$ do município de Imperatriz (MA), tem como perímetro ao Leste o córrego Bom Jesus e a Oeste o Ribeirão dos Frades (CNPT/Ibama, 1993), havendo, ainda, a Este uma área de alagamento sazonal do rio Tocantins (BRASIL, 2011). 
Quadro 1 - Ficha técnica da Reserva Extrativista do Ciriaco

\begin{tabular}{|c|c|}
\hline \multicolumn{2}{|c|}{ Reserva do Ciriaco } \\
\hline Nome da unidade & Reserva Extrativista do Ciriaco \\
\hline Criação & $\begin{array}{l}\text { 20/05/1992 - Decreto } \mathrm{n}^{\circ} 534 \text { da Presidência da } \\
\text { República. Ampliação: 17/06/2010. }\end{array}$ \\
\hline Área & $\begin{array}{l}\text { Inicialmente criada com } 7.523,2578 \mathrm{ha}^{2} \mathrm{e} \\
\text { posteriormente, ampliada para } 8.084,79 \text { hectares. }\end{array}$ \\
\hline Zona de amortecimento proposta & 27.980 hectares. \\
\hline Municípios abrangidos & $\begin{array}{l}\text { Cidelândia, } 78 \mathrm{Km} \text { ao norte de Imperatriz (MA). } \\
\text { Uma pequena franja da porção Sul da UC encontra- } \\
\text { se no município de Imperatriz (ver figura 2). }\end{array}$ \\
\hline Estado & Maranhão \\
\hline $\begin{array}{l}\text { Núcleos habitacionais no interior da } \\
\text { Resex }\end{array}$ & $\begin{array}{l}\text { Núcleos habitacionais: Ciriaco (principal), Bom } \\
\text { Jesus, Varjão e Centro do Olímpio. }\end{array}$ \\
\hline Conselho Deliberativo & Estatuto definido em 20 de maio de 2004. \\
\hline Associação Agroextrativista & Criada em 30 de abril de 1995. \\
\hline Marcos geográficos importantes & $\begin{array}{l}\text { A unidade se localiza a Leste do rio Tocantins, } \\
\text { sendo banhada por suas águas. }\end{array}$ \\
\hline Bioma & $\begin{array}{l}\text { Área de tensão ecológica da Floresta Amazônica } \\
\text { com o Cerrado. }\end{array}$ \\
\hline Formações predominantes & $\begin{array}{l}\text { Cocal fechado/pindoval; cocal esparso; vegetação } \\
\text { ciliar, campo alagadiço e campo abandonado/roça. }\end{array}$ \\
\hline Acesso & $\begin{array}{l}\text { Rodoviário, pela BR-O10, asfaltada e em condições } \\
\text { razoáveis de manutenção, liga Imperatriz até o } \\
\text { entroncamento com a estrada vicinal que conduz à } \\
\text { Cidelândia. Da sede municipal até a Resex, transita- } \\
\text { se por uma estrada de terra perenizada, mas com } \\
\text { pontos de atoleiro na época de chuvas. }\end{array}$ \\
\hline Atividades conflitantes & $\begin{array}{l}\text { caça ilegal, criação de gado, produção de carvão, } \\
\text { turismo. }\end{array}$ \\
\hline Coordenadas geográficas & $\begin{array}{l}\text { Ponto central do povoado de Ciriaco: } 05^{\circ}{ }^{1} 6^{\prime} \\
00,09544^{\prime \prime} \mathrm{S} \text { e } 47^{\circ} 52^{\prime} \text { o8,06035" O }\end{array}$ \\
\hline \multicolumn{2}{|c|}{ Outras coordenadas geográficas de importância para a Resex e sua região próxima } \\
\hline Ciriaco & $\begin{array}{l}\text { Ponto Central do Povoado o5 }{ }^{\circ} 15^{\prime} \text { oo, } 95324^{\prime \prime ~ S ~ e ~} \\
47^{\circ} 49^{\prime} \text { o7,00453" O; Base Avançada do ICMBio } \\
\text { o5 }^{\circ} 15^{\prime} 37,57566^{\prime \prime} \text { S e } 47^{\circ} 49^{\prime} 26,49192^{\prime \prime} \text { O }\end{array}$ \\
\hline Alto Bonito & $\begin{array}{l}\text { Ponto Central do Povoado de Alto Bonito o } 5^{\circ} 1^{\prime} \\
36,68562^{\prime \prime} \text { S e } 47^{\circ} 51^{\prime} \text { o3,68736" O }\end{array}$ \\
\hline Viração & $\begin{array}{l}\text { Ponto Central do Povoado de Viração } 05^{\circ}{ }^{1} 6^{\prime} \\
13,36205^{\prime \prime} \text { S e } 47^{\circ} 52^{\prime} \text { 08,20095" O }\end{array}$ \\
\hline Cidelândia & $\begin{array}{l}\text { Ponto Central da Cidade o5 } 5^{\circ} 10^{\prime} 21,26636^{\prime \prime} \mathrm{S} \text { e } 47^{\circ} \\
46^{\prime} 56,10865^{\prime \prime} O\end{array}$ \\
\hline
\end{tabular}

Fonte: Brasil (2011), com adaptações.

O Quadro 1 contém dados técnicos da Resex, sendo elaborado a partir do levantamento da sua atual estrutura e do seu contexto ambiental, geográfico e social, nos quais ela se encontra inserida.

\footnotetext{
${ }^{2}$ Embora conste uma área um pouco diferente, como pode ser constatado no Decreto $n^{\circ} 534 / 1992$.
} 


\section{RESULTADOS E DISCUSSÃO}

No Quadro 2, a seguir, são expostos os projetos, bem como a finalidade e a origem das principais fontes de recursos, nacionais e internacionais, que apoiam ou já apoiaram o desenvolvimento das quatro comunidades que compõem a Reserva do Ciriaco por meio de sua associação, a Atareco:

Quadro 2 - Projetos - Resex Ciriaco/MA

\begin{tabular}{|c|c|c|c|c|c|}
\hline Fonte & Origem & $\begin{array}{l}\text { Valores } \\
\text { (R\$) }\end{array}$ & Ano & Finalidade & $\begin{array}{c}\text { Situaçã } \\
\text { o }\end{array}$ \\
\hline PNUD & $\begin{array}{l}\text { Internaciona } \\
1\end{array}$ & $27.000,00$ & 1996 & $\begin{array}{l}\text { Compra de forno } \\
\text { para carvão, } \\
\text { burros e carroças. }\end{array}$ & Executado \\
\hline Eletronorte & Nacional & $82.000,00$ & 1998 & $\begin{array}{l}\text { Compra de trator, } \\
\text { forrageira, } \\
\text { batedeira e } \\
\text { outros. }\end{array}$ & Executado \\
\hline $\begin{array}{l}\text { Incra/habitação/fome } \\
\text { nto }\end{array}$ & Nacional & $\begin{array}{l}938.000,0 \\
0\end{array}$ & 2007 & $\begin{array}{l}\text { Construção de } \\
\text { casas e compra } \\
\text { de alimentos. }\end{array}$ & Executado \\
\hline ICMBio & Nacional & $38.100,00$ & 2011 & $\begin{array}{l}\text { Compra de } \\
\text { máquinas para } \\
\text { processamento } \\
\text { de óleo de } \\
\text { babaçu. }\end{array}$ & Executado \\
\hline $\begin{array}{l}\text { Suzano Papel e } \\
\text { Celulose }\end{array}$ & $\begin{array}{l}\text { Nacional/ } \\
\text { Privado }\end{array}$ & $62.903,33$ & 2012 & $\begin{array}{l}\text { Material de } \\
\text { construção, } \\
\text { utensílios e mão } \\
\text { de obra para } \\
\text { construção da } \\
\text { unidade de } \\
\text { beneficiamento } \\
\text { da amêndoa do } \\
\text { babaçu. }\end{array}$ & Executado \\
\hline $\begin{array}{l}\text { Transações penais por } \\
\text { determinação da } \\
\text { Justiça Federal }\end{array}$ & Nacional & $15.000,00$ & 2015 & $\begin{array}{l}\text { Investimento em } \\
\text { equipamentos e } \\
\text { materiais de } \\
\text { construção para a } \\
\text { unidade de } \\
\text { beneficiamento } \\
\text { de amêndoa. }\end{array}$ & Executado \\
\hline $\begin{array}{l}\text { Fundo Amazônia } \\
\text { PPP/Ecos }\end{array}$ & $\begin{array}{l}\text { Nacional/ } \\
\text { Internaciona } \\
\text { l }\end{array}$ & $58.400,00$ & 2015 & $\begin{array}{l}\text { Aquisição de } \\
\text { veículo para } \\
\text { transporte da } \\
\text { amêndoa; } \\
\text { compra de } \\
\text { utensílios e } \\
\text { embalagens para } \\
\text { unidade } \\
\text { produtora. }\end{array}$ & Executado \\
\hline $\begin{array}{l}\text { Suzano Papel e } \\
\text { Celulose }\end{array}$ & $\begin{array}{l}\text { Nacional/ } \\
\text { Privado }\end{array}$ & $5.000,00$ & 2017 & $\begin{array}{l}\text { Material de } \\
\text { construção para } \\
\text { edificação de } \\
\text { galpão para } \\
\text { quebra coletiva } \\
\text { de coco babaçu. }\end{array}$ & Executado \\
\hline
\end{tabular}




\begin{tabular}{|c|c|c|c|c|c|}
\hline Fonte & Origem & $\begin{array}{c}\text { Valores } \\
\text { (R\$) }\end{array}$ & Ano & Finalidade & $\begin{array}{c}\text { Situaçã } \\
\text { o }\end{array}$ \\
\hline $\begin{array}{l}\text { Suzano Papel e } \\
\text { Celulose }\end{array}$ & $\begin{array}{l}\text { Nacional/ } \\
\text { Privado }\end{array}$ & $10.000,00$ & 2017 & $\begin{array}{l}\text { Capital de giro } \\
\text { destinado à } \\
\text { compra de } \\
\text { amêndoa } \\
\text { diretamente das } \\
\text { quebradeiras de } \\
\text { coco para a } \\
\text { produção de óleo. }\end{array}$ & Executado \\
\hline $\begin{array}{l}\text { Suzano Papel e } \\
\text { Celulose }\end{array}$ & $\begin{array}{l}\text { Nacional/ } \\
\text { Privado }\end{array}$ & - & 2018 & $\begin{array}{l}\text { Fortalecimento } \\
\text { dos extrativistas e } \\
\text { resgate das } \\
\text { tradições, } \\
\text { motivando a } \\
\text { gestão, produção } \\
\text { e comercialização } \\
\text { dos produtos } \\
\text { oriundos } \\
\text { principalmente } \\
\text { do coco de } \\
\text { babaçu e do açaí. }\end{array}$ & Executado \\
\hline $\begin{array}{l}\text { Suzano Papel e } \\
\text { Celulose }\end{array}$ & $\begin{array}{l}\text { Nacional/ } \\
\text { Privado }\end{array}$ & - & 2019 & $\begin{array}{l}\text { Promover cerca } \\
\text { de } 1 \text { mil horas em } \\
\text { oficinas de } \\
\text { artesanato } \\
\text { (sabonetes, } \\
\text { cestos de palha } \\
\text { de babaçu, } \\
\text { bolsas, itens com } \\
\text { palha de buriti, } \\
\text { flores de tecido } \\
\text { em tingimento } \\
\text { vegetal). }\end{array}$ & Executado \\
\hline $\begin{array}{l}\text { Fundo Amazônia/PPP } \\
\text { Ecos - Suzano Papel e } \\
\text { Celulose }\end{array}$ & $\begin{array}{l}\text { Nacional/ } \\
\text { Internaciona } \\
\text { l }\end{array}$ & $424.270,82$ & $\begin{array}{l}2020 / 2 \\
2\end{array}$ & $\begin{array}{l}\text { Aperfeiçoamento } \\
\text { do } \\
\text { processamento } \\
\text { do coco de } \\
\text { babaçu e } \\
\text { diversificação da } \\
\text { comercialização, } \\
\text { ampliando a } \\
\text { renda e } \\
\text { conservando os } \\
\text { recursos naturais. } \\
\text { Comunidades } \\
\text { envolvidas: Resex } \\
\text { do Ciriaco; Resex } \\
\text { Mata Grande } \\
\text { (MA), Resex } \\
\text { Extremo Norte } \\
\text { (TO) e nas } \\
\text { comunidades do } \\
\text { entorno, } \\
\text { Petrolina, São } \\
\text { Félix, Olho } \\
\text { D’Água e } \\
\text { Coquelândia } \\
\text { (MA). O projeto }\end{array}$ & $\begin{array}{l}\text { Em } \\
\text { Execução }\end{array}$ \\
\hline
\end{tabular}




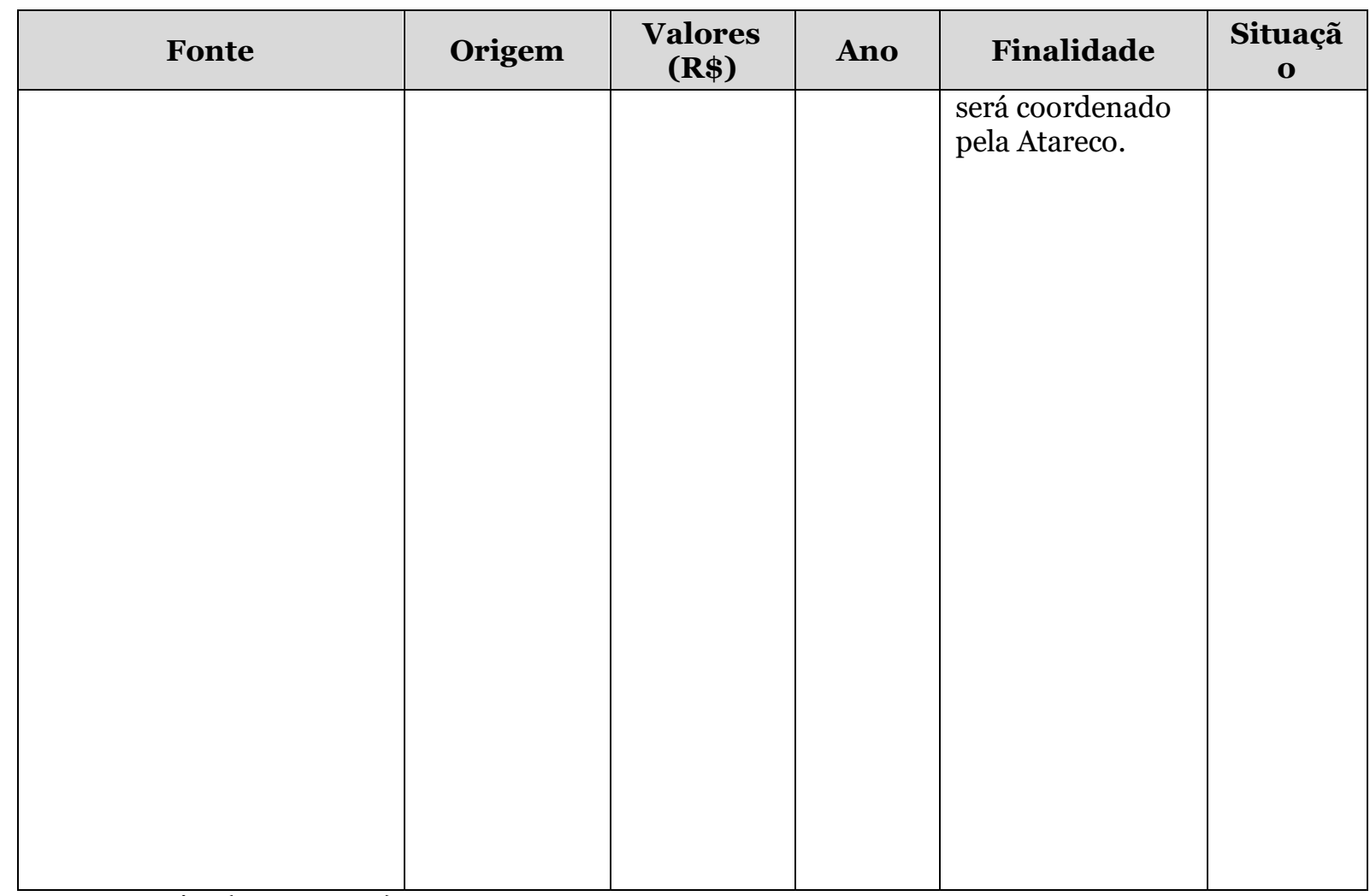

Fonte: Ferreira (2016; 2020).

Pela leitura do Quadro 2, é possível verificar a fonte e a origem dos recursos para os projetos executados e em execução desde o ano de 1996 até 2020, cujos valores foram encaminhados para a Atareco realizar a gestão e a aplicação, desenvolvendo cada etapa conjuntamente com o ICMBio.

Conforme os dados apresentados nota-se que, nos projetos da Resex do Ciriaco, as operações foram voltadas para o significado que principalmente o extrativismo do coco de babaçu possui para a população local.

Projeto I: o primeiro projeto executado na Resex do Ciriaco foi criado no ano de 1996 por meio do Programa das Nações Unidas para o Desenvolvimento (PNUD), que

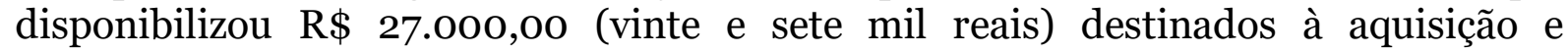
implantação de forno para produzir carvão a partir do coco de babaçu, e também para compra de animais (como burros) e carroças, por serem estes bastante utilizados no transporte de matérias-primas como babaçu, buriti, bacuri, entre outros. Vale registrar que o PNUD é a rede de desenvolvimento global da Organização das Nações Unidas que faz parcerias com pessoas em todas as instâncias da sociedade para ajudar na construção de nações que possam resistir a crises, sustentando e conduzindo um crescimento capaz de melhorar a qualidade de vida para todos.

Projeto II: o projeto seguinte contou com a contribuição da Eletronorte que, em 1998, disponibilizou $\mathrm{R} \$ 82.000,00$ (oitenta e dois mil reais) para a compra de um trator e equipamentos como forrageira, batedeira e outros. Esses investimentos também contribuíram para o fortalecimento do projeto de processamento do coco de babaçu. A Eletronorte reforça seu compromisso em levar energia e qualidade de vida para a região Amazônica, assim como enfatiza os aspectos éticos, sociais e ambientais. Tem como referência programas e projetos sociais com vistas à qualidade de vida e ao desenvolvimento sustentável das comunidades localizadas nas regiões da sua área de abrangência (ELETRONORTE, 2017). 
Projeto III: no intervalo entre os anos de 1998 e 2006 não foi verificado nenhum investimento em projetos para Resex, entretanto, a partir de 2007, a contribuição do Instituto de Colonização e Reforma Agrária (Incra), no valor de $\mathrm{R} \$$ 938.00o,0o (novecentos e trinta e oito mil reais), possibilitou a construção de 113 casas e também a compra de alimentos para as famílias de extrativistas da Resex, retomando a expectativa das comunidades em relação à implementação de seus projetos. O Incra é uma autarquia federal cuja missão prioritária é executar a reforma agrária e realizar o ordenamento fundiário nacional. Criado pelo Decreto $\mathrm{n}^{0} \mathbf{1 . 1 1 0}$, de 9 de julho de 1970, atualmente o Incra está implantado em todo o território nacional por meio de 30 superintendências regionais (INCRA, 2017).

Ao realizar o levantamento dos projetos implementados na Resex, foram identificados alguns dos princípios característicos das instituições de êxito, elaboradas por Ostrom (2011): i) as regras definidas têm de ser adequadas às condições locais (época, espaços, tecnologias disponíveis, quantidades de recursos disponíveis...); e ii) os utilizadores participam na definição/adaptação das próprias regras e acordos coletivos. Tais princípios indicam relação com as normas definidas no plano de manejo e que são cumpridas em razão do comprometimento dos gestores dos projetos (ICMBio e Atareco) e dos comunitários, conforme esta pesquisa constatou nas ações implementadas a partir do ano de 1996 até este ano, 2020.

Projeto IV: o Instituto Chico Mendes de Conservação da Biodiversidade (ICMBio) também destinou o recurso de $\mathrm{R} \$ 38.100,00$ (trinta e oito mil e cem reais) em 2011 visando à compra de máquinas para o processamento do coco de babaçu, mais especificamente para a extração do óleo, que é um produto nobre e valorizado no mercado nacional. O ICMBio é uma autarquia em regime especial. Cabe ao instituto executar as ações do Sistema Nacional de Unidades de Conservação, podendo propor, implantar, gerir, proteger, fiscalizar e monitorar as unidades de conservação instituídas pela União (ICMBio, 2017).

Projeto V: no ano seguinte, 2012, a Suzano Papel e Celulose destinou R\$ 62.903,33 (sessenta e dois mil, novecentos e três reais e trinta e três centavos) para aquisição de material de construção, utensílios e contratação de mão de obra para construção da unidade de beneficiamento da amêndoa do babaçu. Ressalta-se que todo investimento no processamento do coco de babaçu é bastante desejável pelas comunidades da Resex por ser os seus babaçuais o maior bem de uso comum (SUZANO, 2017).

Projeto VI: no ano de 2015, o recurso no valor de $\mathrm{R} \$ 15.000,00$ (quinze mil reais) foi adquirido por meio de transações penais, por determinação da Justiça Federal. O mesmo foi utilizado na aquisição de equipamentos e de materiais de construção para a unidade de beneficiamento de amêndoa do coco de babaçu.

Projeto VII: o Fundo Amazônia Programa de Pequenos Projetos Ecossociais (PPP/Ecos), por meio de recursos de origem nacional e internacional, disponibilizou $\mathrm{R} \$ 58.400,00$ (cinquenta e oito mil e quatrocentos reais) também no ano de 2015 para a aquisição de veículo para transporte da amêndoa de coco de babaçu, compra de utensílios e de embalagens para a unidade produtora. O Fundo Amazônia tem por finalidade captar doações para investimentos não reembolsáveis em ações de prevenção, monitoramento e combate ao desmatamento, e de promover a conservação e uso sustentável das florestas no Bioma Amazônia, nos termos do Decreto $\mathrm{n}^{0}$ 6.527, de $1^{\circ}$ de agosto de 2008 (ISPN, 2018).

Projeto VIII: no ano de 2017, a empresa Suzano Papel e Celulose destinou recurso de $\mathrm{R}$ \$ 5.000,00 (cinco mil reais) para aquisição de material para construção de galpão com o fim de abrigar os participantes na quebra coletiva de coco babaçu. Foi dedicado também o recurso de $\mathrm{R} \$ 10.000,00$ (dez mil reais) para investir no capital de 
giro destinado à compra de amêndoa diretamente das quebradeiras de coco de babaçu para a produção de óleo (SUZANO, 2017).

Projeto IX: o Projeto Extrativismo Sustentável (PROJETOS..., 2020), da Suzano Papel e Celulose, apoia mais de duzentas famílias nas comunidades: Olho D’Água, Coquelândia, São Félix, Petrolina, KM 1700 e, entre estas, a Resex do Ciriaco, com o objetivo de fortalecer os extrativistas de produtos florestais não madeireiros e o resgate de práticas tradicionais. Essa ação motiva: i) gestão; ii) produção; e iii) comercialização dos produtos oriundos principalmente do coco de babaçu e do açaí. O Projeto Pindowa, iniciado em 2019, promoveu mais de 1 mil horas de oficinas de capacitação em artesanato, voltadas para a produção de sabonetes artesanais, cestos de palha de babaçu, bolsas, itens com palha de buriti, flores de tecido em tingimento vegetal. Os produtos das oficinas foram expostos na $2^{\text {a }}$ Mostra Matriz Brasileira, em São Paulo, no Instituto Tomie Ohtake.

Projeto X: o projeto Suzano Papel e Celulose/PPP Ecos - em execução - consiste em um projeto para envolver os grupos de quebradeiras de coco e suas organizações localizadas na Resex do Ciriaco, em Cidelândia/MA; na Resex Mata Grande, em Davinópolis/MA; na Resex Extremo Norte, em Carrasco Bonito/TO; e nas comunidades do entorno, Petrolina, São Félix, Olho D’Água e Coquelândia, situadas no município de Imperatriz. Vale ressaltar que a Atareco será responsável pela coordenação do referido Projeto (Figura 2).

O objetivo geral dessa iniciativa é melhorar as condições de vida das quebradeiras de coco de babaçu da Região Tocantina, através do aperfeiçoamento do processamento do coco babaçu e diversificação da comercialização, ampliando a renda e conservando a natureza. Esse projeto também atende aos objetivos específicos de: i) fortalecer as organizações e a articulação das quebradeiras da Região Tocantínia; ii) aumentar e aperfeiçoar o extrativismo e processamento coletivo de coco babaçu; iii) ampliar e diversificar a comercialização dos produtos do babaçu; iv) realizar a gestão participativa do projeto, socializando seus resultados e aprendizados com outras comunidades (PROJETO BABAÇU FONTE DE VIDA, 2019).

Figura 2 - Localização do Projeto

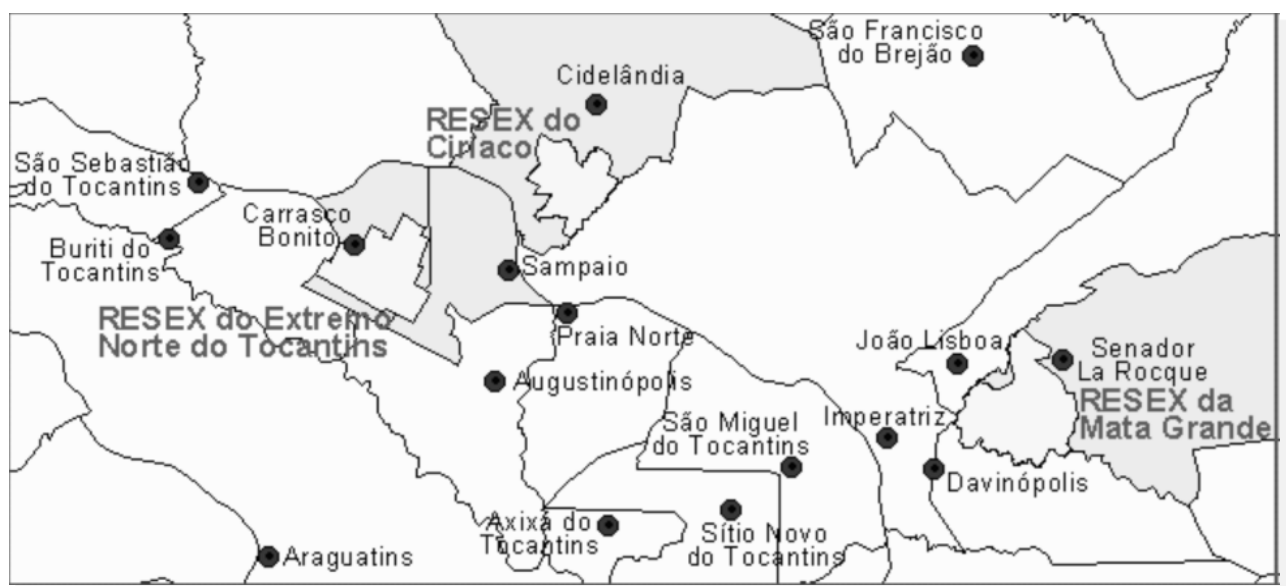
(2019).

Fonte: Projeto Babaçu Fonte de Vida: quebradeiras articuladas e cuidando da natureza

Como observado no Quadro 2, o recurso para a execução dessa ação é proveniente do Programa de Pequenos Projetos Ecossocial (PPP-ECOS), com a contrapartida da Suzano Papel e Celulose. 
Desse modo, os responsáveis pela gestão dos projetos (Atareco, ICMBio), desenvolvem atividades integradas ao plano de manejo. Na Resex do Ciriaco, dois elementos são estratégicos para a gestão dos recursos naturais de uso comum no presente e em médio prazo:

(i) A reaproximação entre os diversos grupos locais, separados por vários anos de conflito e que hoje se recusam a colaborar entre si em quaisquer atividades, impedindo soluções cooperativas para o aproveitamento comercial do babaçu e reduzindo o consenso nas consultas públicas realizadas, bem como reduzindo, senão impedindo, a aplicação de métodos rápidos que demandam pequenas amostragens populacionais.

(ii) A identificação de uma alternativa economicamente viável para o aproveitamento do coco babaçu e a negociação, na comunidade e entre ela e o ICMBio, sobre o significado cultural da produção de carvão (BRASIL, 2011, p. 19).

Tais estratégias estimulam a reaproximação dos grupos comunitários criando um ambiente de cooperação mútua essencial para a gestão coletiva da Resex. Desse modo, outras ações voltadas para o aproveitamento do coco de babaçu são imprescindíveis para a sustentabilidade da unidade de conservação, pelos seguintes motivos: i) a Resex foi criada em função do extrativismo do babaçu; ii) a diminuição da quebra do coco para a retirada da amêndoa está causando a perda no mercado de óleo de babaçu; iii) a produção do carvão do coco inteiro é fundamental para a geração de renda das famílias de Ciriaco e não pode ser interrompida, pois tem alta relevância econômica (BRASIL, 2011).

Diante dos projetos expostos, o processo de monitoramento é realizado pelos comunitários (residentes da Resex) e seus respectivos representantes no Conselho Deliberativo. Esta prática condiz com o sexto princípio da teoria da governança, pois o monitoramento das regras estabelecidas pelos utilizadores da Resex é realizado constantemente, visando garantir que estas sejam respeitadas, ficando os transgressores passíveis de penalizações (OSTROM, 1990).

Por meio de reuniões técnicas, os profissionais buscam a contextualização regional da Resex do Ciriaco, seguida de análises socioeconômicas da população local, bem como da apresentação, análise de formas de organização, representação social e de práticas produtivas, uso e manejo dos recursos naturais (ICMBIO, 2011).

Ao retomar a teoria da governança, alguns dos princípios descritos por Ostrom são atendidos em consenso pelos membros da Atareco e do Conselho Deliberativo, iniciando pela demarcação clara das fronteiras dos recursos de uso comum da Resex. As regras para desenvolver qualquer projeto são definidas e adequadas à realidade das cinco comunidades que compõem a reserva: i) os acordos são coletivos entre os utilizadores da Resex; ii) o Conselho Deliberativo e a Atareco buscam equilíbrio quanto aos benefícios proporcionados pela gestão comum dos projetos implementados; iii) o monitoramento das regras de sustentabilidade é realizado e respeitado entre os comunitários (OSTROM, 1990).

A Resex do Ciriaco, como boa parte das unidades de conservação no Brasil, apesar dos obstáculos, destaca-se entre as demais da Amazônia legal, por meio da gestão do ICMBio, que busca, constantemente, o encaminhamento para os impasses no desenvolvimento de projetos e a cooperação dos atores envolvidos. Essa atuação reflete-se no bom desempenho da gestão coletiva dos projetos, conforme constatado nesta pesquisa. 


\section{CONCLUSÃO}

A partir desta pesquisa, foi possível discorrer sobre os projetos desenvolvidos (por meio de recursos públicos e/ou privados) na comunidade do Ciriaco e identificar se a implementação destes está condizente com as regras estabelecidas em seu Plano de Manejo Participativo.

Nesse sentido, evidenciou-se que a realização de cada iniciativa aconteceu por meio da gestão coletiva desempenhada pela Atareco e pelo ICMBio, que norteiam suas atividades, conforme o Plano de Manejo (ICMBIO, 2011), o qual determina abordar as dimensões ambientais, sociais, econômicas, políticas e culturais relativas a essa unidade de conservação federal.

Constatou-se que, no caso de uma reserva extrativista, a implementação dessas iniciativas tem especificidades a serem consideradas, pois não se trata de gerenciar operações em uma empresa do setor público ou empresarial, e sim participar de ações numa unidade de conservação que é um espaço onde o principal foco é a gestão dos recursos naturais de uso comum (água, solo e floresta) e o respeito às tradições culturais das comunidades. Por isso, a sustentabilidade socioeconômica e ambiental da Resex em questão depende do empenho de seus gestores, bem como dos comunitários, para aplicar adequadamente os recursos financeiros na implementação dos projetos.

Assim, o plano de manejo constitui-se, para os comunitários residentes da Resex, num instrumento de alta relevância em todos os aspectos, pois tem como objetivo apoiar a gestão da UC. Portanto, o plano deve estar adequado às especificidades da UC nos aspectos sociais e econômicos, priorizando as demandas imediatas e direcionando a gestão para o alcance de uma comunidade sustentável e duradoura.

No levantamento dos projetos executados ou em execução no período de 1996 até 2020, a parceria entre Atareco, ICMBio e demais comunitários contribuiu para realização de cada etapa do desenvolvimento das ações, em que todos os atores envolvidos compartilharam suas experiências e estabeleceram acordos coletivos para alcançar o propósito de cada empreendimento, embora algumas dificuldades na conservação ambiental ainda tenham sido constatadas.

As comunidades e propriedades particulares (fazendas) localizadas no entorno da Resex do Ciriaco, em algumas situações, são potencialmente prejudiciais para a sustentabilidade da UC, pois os impactos produzidos pelas práticas de pecuária e silvicultura, pelo aumento das atividades econômicas na região e pelo tráfego de veículos e de pessoas na área trazem consequências negativas. Tais efeitos, tais como o aumento da caça ilegal, do desgaste do solo, da quantidade de lixo produzido e do uso inadequado das águas, têm se acentuado nos últimos anos.

Este estudo permitiu averiguar a relevância de projetos voltados a atender às demandas de uma Resex, a garantia do uso sustentável dos recursos naturais de uso comum (biodiversidade) e o respeito às tradições culturais das comunidades de acordo com as regras estipuladas no seu Plano de Manejo. Desse modo, também contribui para ampliar a compreensão acerca da implementação de empreendimentos sociais voltados para as comunidades extrativistas. 


\section{REFERÊNCIAS}

BRASIL. Ministério do Meio Ambiente. O Sistema Nacional de Unidades de Conservação da Natureza - SNUC. Brasília: MMA, 2011. Disponível em http://www.mma.gov.br/estruturas/240/_publicacao/240_publicacao05072011052 536.pdf. Acesso em: 18 jul. 2017.

BRASIL. Ministério do Meio Ambiente. Plano de Manejo. Brasília: MMA, 2011. On-line. Disponível em https://www.mma.gov.br/areas-protegidas/unidades-deconservacao/plano-de-manejo. Acesso em: 18 jul. 2020.

Associação dos Trabalhadores Agroextrativistas da Resex do Ciriaco - ATARECO. Projeto Babaçu Fonte de Vida: quebradeiras articuladas e cuidando da natureza. Cidelândia, 2019.

CNPT/Ibama. Relatório de Vistoria e Avaliação de Imóveis Rurais na Gleba "Campo Alegre” no Município de Imperatriz, Estado do Maranhão”. Mimeo. Ministério do Meio Ambiente, CNPT/Ibama, Brasília, 1993.

ELETRONORTE. Responsabilidade social. Disponível em:

http://www.eletronorte.gov.br/opencms/opencms/pilares/responsabilidadeSocial/. Acesso em: 17 jul. 2017.

FERREIRA, Fernubia. Pré projeto - Reserva Ciriaco. Publicação on-line [mensagem pessoal]. Mensagem recebida por fernubia.ferreira@icmbio.gov.br em 31 set. 2016.

FERREIRA, Fernubia. Projeto. Publicação on-line [mensagem pessoal]. Mensagem recebida por fernubia.ferreira@icmbio.gov.br em 30 de jul. de 2020.

GODOY, Arilda Schmid. Introdução à pesquisa qualitativa e suas possibilidades. Revista de Administração de Empresas, São Paulo, v. 35, n. 2, p. 57-63, abr. 1995 .

HESS, Charlotte; OSTROM, Elinor. Understanding knowledge as a commons: from theory to practice. Cambridge: The MIT Press, 2007. $383 \mathrm{p}$.

ICMBIO - INSTITUTO CHICO MENDES DE CONSERVAÇÃO DA BIODIVERSIDADE. O instituto. Brasília: ICMBio, 2017. Disponível em: http://www.icmbio.gov.br/portal/oinstituto. Acesso em: 18 jul. 2017.

ICMBIO - INSTITUTO CHICO MENDES DE CONSERVAÇÃO DA BIODIVERSIDADE. Diretoria de Unidades de Conservação de uso Sustentável e Populações Tradicionais. Plano de Manejo Participativo da Reserva Extrativista do Ciriaco. Cidelândia, 2011.

ICMBIO - INSTITUTO CHICO MENDES DE CONSERVAÇÃO DA BIODIVERSIDADE. Planos de manejo. Brasília: ICMBio, 2020. On-line. Disponível em: https://www.icmbio.gov.br/portal/unidadesdeconservacao/planosde-manejo. Acesso em: 18 jul. 2020. 
INCRA - INSTITUTO DE COLONIZAÇÃO E REFORMA AGRÁRIA. O Incra. Disponível em: http://www.incra.gov.br/institucional_abertura. Acesso em: 18 jul. 2017.

ISPN - INSTITUTO SOCIEDADE POPULAÇÃO E NATUREZA. PPP/Ecos: Paisagens Produtivas Ecossociais. Brasília, 2018. On-line. Disponível em: http://www.ispn.org.br/projetos/ppp-ecos-programa-pequenos-projetosecossociais/. Acesso em: 18 jul. 2017.

OLIVEIRA, Thiago. José. Arruda. Mapa. Publicação on-line [mensagem pessoal]. Mensagem recebida por thiago.arruda85@gmail.com em 14 set. 2017.

OSTROM, Elinor. Governing the commons: the evolution of institutions for collective action. Cambridge: Indiana University Press, 1990. 402 p.

OSTROM, Elinor. Institutional rational choice: an assessment of the IAD Framework. In: SABATIER, P. A. (Ed.). Theories of the policy process. Boulder, CO: Westview Press, 1999.

PROJETOS apoiados pela Suzano beneficiaram mais de 10 mil pessoas em 2019. O Maranhense, São Luís, 27 fev. 2020. On-line. Disponível em:

http://omaranhense.com/projetos-apoiados-pela-suzano-beneficiaram-mais-de-10mil-pessoas-em-2019/. Acesso em: 17 abr. 2020.

RESERVA DO CIRIACO. Parceiros. Disponível em http://resexciriaco.eco.br/parceiros/. Acesso: 17 jul. 2017.

SIMÕES, João; MACEDO, Marta; BABO, Pilar. Elinor Ostrom: “Governar os comuns". 2011. Disponível em http://www.fep.up.pt/docentes/

cchaves/Simoes_Macedo_Babo_2011_Ostrom.pdf. Acesso em: 25 ago. 2016.

SUZANO Papel e Celulose. Institucional. Disponível em http://www.suzano.com.br/institucional/perfil. Acesso em: 18 jul. 2017.

VERGARA, Sylvia Constant. Projetos e relatórios de pesquisa em administração.16. ed. São Paulo: Atlas, 2016. 104 p. 
Submetido em 21/5/202O

Aprovado em 2O/12/2O2O

\section{Sobre o(s) Autor(es):}

\section{Lucélia Neves}

Programa de Pós Graduação em Desenvolvimento Regional - PGDR / Planejamento Urbano e Regional/Demografia. Email: luceliadr@gmail.com

\section{Alex Pizzio}

Programa de Pós Graduação em Desenvolvimento Regional - PGDR / Planejamento Urbano e Regional/Demografia. Email: alexpizzio@mail.uft.edu.br

\section{Waldecy Rodrigues}

Programa de Pós Graduação em Desenvolvimento Regional - PGDR / Planejamento Urbano e Regional/Demografia. Email: waldecy@uft.edu.br 